\title{
Antimicrobial activity of alexidine, chlorhexidine and cetrimide against Streptococcus mutans biofilm
}

Matilde Ruiz-Linares ${ }^{1 *}$, Carmen Maria Ferrer-Luque ${ }^{2}$, Teresa Arias-Moliz ${ }^{3}$, Paula de Castro ${ }^{4}$, Beatriz Aguado ${ }^{4}$ and Pilar Baca ${ }^{5}$

\begin{abstract}
Background: The use of antimicrobial solutions has been recommended to disinfect demineralized dentin prior to placing the filling material. The aim of this study was to evaluate the ability of several antimicrobials in controlling Streptococcus mutans (SM) biofilm formed in dentin.

Methods: Antimicrobial activity of $0.2 \%$ and $2 \%$ chlorhexidine (CHX), $0.2 \%$ cetrimide (CTR) and $0.2 \%, 0.5 \%, 1 \%$ and $2 \%$ alexidine (ALX) was assayed on 1-week SM biofilm formed on standardized coronal dentin blocks. Results of SM biofilm antimicrobial activity by different protocols were expressed as the kill percentage of biofilm and the term "eradication" was used to denote the kill of 100\% of the bacterial population. To compare the efficacies of the different protocols the Student t test was used, previously subjecting data to the Anscombe transformation.

Results: All ALX concentrations tested and 0.2\% CTR achieved a kill percentage higher than 99\%, followed by $2 \%$ CHX with percentages above $96 \%$ (no statistically significant difference among them). Whereas 2\% ALX and 0.2\% CTR respectively showed eradication in 10 and 9 of the twelve specimens, $0.2 \% \mathrm{CHX}$ did not produce eradication in any case.
\end{abstract}

Conclusions: The present study shows that, when used for one minute, $2 \%$ and $1 \%$ alexidine, and $0.2 \%$ cetrimide, achieve eradication of Streptococcus mutans biofilm in most specimens when applied to a dentin-volumetric model.

Keywords: Alexidine, Biofilm, Cetrimide, Chlorhexidine, Streptococcus mutans

\section{Background}

Dental caries is a chronic and transmissible disease characterized by demineralization of the tooth due to acids produced by bacteria in biofilms formed on its surface. Streptococcus mutans (SM) is considered one of the most cariogenic bacteria present in human dental biofilm [1] and in dentin caries lesions [1-3]. Its metabolic activity is closely related to the initiation and progression of dental caries [2].

The treatment of deep caries lesions has traditionally involved removal of all the soft demineralized dentin before a filling is placed. However, operative dentistry is now moving away from complete caries removal to an

\footnotetext{
* Correspondence: matr@ugr.es

${ }^{1}$ Department of Paediatric Dentistry, School of Dentistry, University of Granada, Campus de Cartuja, Colegio Máximo s/n, Granada, Spain Full list of author information is available at the end of the article
}

ultraconservative approach, preserving tooth structure and preventing pulpal injury [3]. Clinical procedures involving incomplete caries removal are advocated based on the concept that deep carious dentin lesions comprise two distinct layers: an outer layer or infected dentin, highly contaminated and not recoverable, and an inner layer of affected dentin -less frequently contaminated with bacteria and preserving the cross-banded ultra structure of the collagen matrix - capable of being remineralized. Within this context, the objective of partial caries removal is to eliminate only superficial carious dentin that is highly infected, whereas dentin able to remineralize is maintained [4].

Microbiological and clinical studies have shown that the number of bacteria decreases during incomplete carious removal followed by adequate cavity sealing, and that lesions are clinically arrested [5-10]. Although a limited 
number of microorganisms persist under restorations a few months after the partial caries removal and sealing $[5,8,9]$, some cariogenic bacteria may be found within the remaining microorganisms, such as Streptococcus mutans, which is currently found on sealed carious dentin [2,6-9]. Moreover, it has recently been reported that the genotypic diversity of SM decreased after partial dentin removal and sealing, whereas the virulence traits of SM were unchanged, maintaining the same cariogenic potential [9].

In this context, efforts to eliminate or reduce residual bacteria in affected dentin aiming to decrease the risk of caries progression persist. Among possible strategies, antimicrobial solutions have been recommended to clean the cavity prior to introducing the filling material [10]. Of all available antimicrobials in dentistry, chlorhexidine $(\mathrm{CHX})$ is still the most frequently used agent to reduce plaque aiming at caries control [11]. CHX is widely used as an antimicrobial agent for disinfection before the placement of restorations $[10,12]$. It has demonstrated its effectiveness against bacteria associated with dental caries, and SM has been shown to be particularly sensitive to CHX [13]. Due to its broad antimicrobial spectrum (i.e. against gram positive/negative bacteria and fungi), $\mathrm{CHX}$ has been used to adjunctively treat either endodontic or periodontal diseases and to arrest/prevent caries progression [11]. At the concentrations used clinically, the biocompatibility of $\mathrm{CHX}$ is acceptable having a low degree of toxicity [14]. In dentin samples with bacterial biofilm, $2 \% \mathrm{CHX}$ is effective in reducing total bacteria count, SM, lactobacilli [15] and Enterococcus faecalis [16], but it does not achieve eradication. Similarly to CHX, alexidine (ALX) is a bisbiguanide disinfectant, with faster bactericidal action [17]. ALX has been previously used as a mouthwash [18] and contact lens solution [19] and is being evaluated for possible use in endodontics [20]. Both $1 \%$ and $2 \%$ ALX concentrations have shown eradication of E. faecalis biofilm [21] and its substantivity in dentin has been demonstrated [22]. Furthermore, as compared with CHX, ALX shows lower toxicity when applied topically to corneal tissues in vivo [23]. Cetrimide (CTR) is a cationic surfactant, a quaternary ammonium derivative, which has demonstrated its effectiveness against gram-positive and gram-negative bacteria, also showing antifungal activity [24]. Generally applied as a topic antiseptic, it is not toxic at the concentrations of use [25]. It is scarcely irritanting and it reduces the surface tensión of liquids, favoring their entry into places of difficult access, such as dentin tubules [26]. These features justify its inclusión as a component of irrigating solutions used in endodontics. At the concentrations used for root canal irrigation, it has less toxicity than endodontic irrigants such as sodium hypochloride [27]. In addition to eradicating $E$. faecalis biofilms in vitro [28] and ex vivo [16], it exerts residual antimicrobial activity over time [29]. As irrigating solutions in endodontics, 0.2\% CTR have shown their effectiveness [16]. It was recently shown that $0.2 \%$ cetrimide provides longer substantivity than $0.2 \%$ chlorhexidine and nearly as long as that of $2 \%$ chlorhexidine in a dentin-volumetric model [29]. There is no clear evidence to date of its effectiveness as a cavity disinfectant, but it has been effective in vitro, combined with polyacrylic acid, in eliminating bacteria associated with residual caries [30]. The aim of this study was therefore to evaluate the antimicrobial activity of chlorhexidine, cetrimide and alexidine against $S$. mutans biofilm, using a dentin-volumetric test.

\section{Methods and materials}

\section{Bacteria strain and antimicrobial solutions}

The bacteria used in this study were S. mutans (SM) (ATCC 25175) from the Spanish Type Culture Collection (CECT, Burgasot, Valencia). The bacteria were kept in tubes containing Brain Heart Infusion (BHI) agar (Scharlau Chemie SA, Barcelona, Spain), at $4^{\circ} \mathrm{C}$ for further use in the experiments. From the subculture of SM, a 1 McFarland standard suspension was prepared in $\mathrm{BHI}$ broth and subsequently diluted to obtain a suspension of approximately $6 \times 10^{7}$ colony-forming units per milliliter (CFU/mL).

The solutions tested were $0.2 \%$ and $2 \%$ CHX (Guinama, Alboraya, Spain), 0.2\%, 0.5\%, 1\% and 2\% ALX (Alexidine dihydrochloride, Santa Cruz Biotechnology Inc., Heidelberg, Germany) and 0.2\% CTR (Sigma-Aldrich Chemie, Steinheim, Germany).

\section{Preparation of dentin blocks}

The protocol was approved by the Ethics Committee of the University of Granada, Spain. Twenty-seven unerupted extracted third human molars were stored in $0.1 \%$ thymol solution at $4^{\circ} \mathrm{C}$. In preparing the dentin blocks, we followed the methodology described in a previous article [16]. The teeth were sectioned, and the two apical thirds of the roots were discarded, as was the occlusal coronal enamel, leaving a flat coronal dentin surface. This slice was cut into serial blocks. Four dentin blocks without enamel/tooth were then adjusted using a calibrator and polished with 150-, 220-, and 600-grit silicon carbide papers to obtain $2 \times 2 \times 1.2 \mathrm{~mm}$ (width $\times$ length $\times$ height) specimens. After sterilization, they were kept in a sterile saline solution until use shortly thereafter. The smear layer formed during preparation of the dentin blocks was eliminated by submerging them in $37 \%$ orthophosphoric acid for 15 seconds, after which they were sterilized. The specimens were randomly assigned to the different groups: $0.2 \%$ and $2 \% \mathrm{CHX} ; 0.2 \%, 0.5 \%, 1 \%$ and 2\% ALX; 0.2\% CTR; and one control group. Thus, each of the four specimens per tooth was tested in a different group. Two specimens per group, obtained from four additional molars, were studied under scanning electron 
microscopy (SEM). After sterilization, the specimens were incubated in $\mathrm{BHI}$ for 24 hours at $37^{\circ} \mathrm{C}$ to ensure no bacterial contamination.

\section{Biofilm antimicrobial activity test}

The wells of 96-well microtiter plates (Nunclon Delta Surface; Nunc, Roskilde, Denmark) were inoculated with $180 \mu \mathrm{L}$ of the initial bacterial suspension. Twelve wells were inoculated with sterile BHI for the sterility control. The sterile dentin blocks were submerged in the inoculated wells, and they were incubated on a rocking table (Swing Sw 8 10000-0015; OVAN, Badalona, Spain) for 1 week at $37^{\circ} \mathrm{C}$ in an anaerobic atmosphere. The BHI was refreshed daily to ensure the growth of SM on the dentin blocks, and the purity of the cultures was checked at regular intervals. Dentin specimens with SM biofilm were rinsed with $120 \mu \mathrm{L} 0.9 \%$ saline solution for 2 minutes to remove bacteria that were not strongly adhered to the biofilm.

The antimicrobial activity assay was performed in the 96-well microtiter plates with $100 \mu \mathrm{L}$ of the antimicrobial solutions per well. The saline rinsed specimens, dried with sterile paper disks, were then placed in the wells in contact with the disinfecting solutions for 1 minute. After subjecting the dentin blocks to the disinfectant protocols, sterile absorbent paper disks (IVD; Becton, Dickinson and Company, Sparks, MD) were used to eliminate any excess solution from the specimens. They were placed in Eppendorf tubes with $200 \mu \mathrm{L}$ BHI, vortexed for 10 seconds, and then sonicated for 10 minutes to ensure biofilm recovery. Disrupted biofilm cultures were diluted serially and plated for viable cell counting.

\section{Scanning electron microscopy}

For SEM analysis, the specimens were washed in sterile phosphate-buffered saline and then fixed with a $4 \%$ glutaraldehyde solution for $24 \mathrm{~h}$. After that, biofilms were dehydrated in graded ethanol series (50, 70, 90, and 100\%), dried for $24 \mathrm{~h}$, and sputter coated with gold-palladium. The samples were then analyzed by SEM (Hitachi, S-510, Japan) at $25 \mathrm{Kv}$.

\section{Statistical analysis}

Results of SM biofilm antimicrobial activity by different protocols were expressed as the kill percentage of biofilm, calculated as follows: $\left(1-\right.$ [mean $C F U_{\text {antimicrobial solution' }}$ mean $\left.\left.\mathrm{CFU}_{\text {control }}\right]\right) \times 100$ ). The term "eradication" was used to denote the kill of $100 \%$ of the bacterial population. To compare the efficacies of the different protocols, the Student $\mathrm{t}$ test was used, previously subjecting data to the Anscombe transformation.

\section{Results}

The negative controls showed no bacterial growth. The results of the antimicrobial activity are shown in Table 1.
Table 1 Antimicrobial activity against Streptococcus mutans biofilm of chlorhexidine, cetrimide and alexidine solutions

\begin{tabular}{lllll}
\hline $\begin{array}{l}\text { Antimicrobial } \\
\text { solution } \\
\text { (n= 12/group) }\end{array}$ & $\begin{array}{l}\text { Minimum } \\
\text { CFUs/mL }\end{array}$ & $\begin{array}{l}\text { Maximum } \\
\text { CFUs/mL }\end{array}$ & $\begin{array}{l}\text { Units } \\
\text { with E }\end{array}$ & $\begin{array}{l}\text { Kill percentage mean } \\
\text { (standard deviation)* }\end{array}$ \\
\hline 2\% CHX & 0 & 61.000 & $6 / 12$ & $96.57(9.82)^{1,3}$ \\
0.2\% CHX & 3.000 & 59.000 & $0 / 12$ & $85.18(10.60)^{2}$ \\
2\% ALX & 0 & 19 & $10 / 12$ & $99.99(0.0033)^{1}$ \\
$1 \%$ ALX & 0 & 72 & $8 / 12$ & $99.99(0.014)^{1}$ \\
0.5\% ALX & 0 & 3.600 & $7 / 12$ & $99.78(0.58)^{1,3}$ \\
$0.2 \%$ ALX & 0 & 4.700 & $5 / 12$ & $99.56(0.86)^{3}$ \\
$0.2 \%$ CTR & 0 & 2.800 & $9 / 12$ & $99.84(0.45)^{1,3}$ \\
\hline
\end{tabular}

CHX: chlorhexidine; ALX: alexidine; CTR: cetrimide.

E: eradication or $100 \%$ kill percentage with respect to the control. Control values: Minimum: 60.000, maximum: 380.000, mean (standard deviation): 178.333 (105.298)

${ }^{* 1,2,3}$ The same number shows differences that are not statistically significant determined by Student $T$ test previously subjecting data to

Anscombe transformation.

$p$ value of comparisons: $2 \% \mathrm{CHX}$ vs $0.2 \% \mathrm{CHX}: p<0.001,2 \% \mathrm{CHX}$ vs $2 \% \mathrm{ALX}$ : $p=0.134,2 \%$ CHX vs 1\% ALX: $p=0.144,2 \%$ CHX vs $0.5 \%$ ALX: $p=0.267,2 \%$ CHX vs $0.2 \%$ ALX: $p=0.424,2 \%$ CHX vs $0.2 \%$ CTR: $p=0.221,0.2 \%$ CHX vs $2 \%$ ALX: $\mathrm{p}<0.001$, $0.2 \%$ CHX vs 1\% ALX: $p<0.001,0.2 \%$ CHX vs $0.5 \%$ ALX: $p<0.001,0.2 \%$ CHX vs $0.2 \%$ ALX: $p<0.001,0.2 \%$ CHX vs $0.2 \%$ CTR: $p<0.001,2 \%$ ALX vs $1 \%$ ALX: $p=0.174,2 \%$ ALX vs $0.5 \%$ ALX: $p=0.127,2 \%$ ALX vs $0.2 \%$ ALX: $p=0.04,2 \%$ ALX vs $0.2 \% C T R$ : $p=0.212,1 \%$ ALX vs $0.5 \%$ ALX: $p=0.156,1 \%$ ALX vs $0.2 \%$ ALX: $p=0.04,1 \%$ ALX vs $0.2 \%$ CTR: $p=0.275,0.5 \%$ ALX vs $0.2 \%$ ALX: $p=0.413,0.5 \%$ ALX vs $0.2 \%$ CTR: $p=0.713,0.2 \%$ ALX vs $0.2 \%$ CTR: $p=0.247$

All tested antimicrobial solutions obtained a high kill percentage of SM biofilms with respect to the control. Whereas $2 \%$ ALX and $0.2 \%$ CTR respectively showed eradication in 10 and 9 of the 12 specimens, $0.2 \%$ CHX did not produce eradication in any specimen. SEM images showed a reduction of bacteria within the biofilms compared with the control group (Figure 1). All the ALX concentrations tested, as well as $0.2 \%$ CTR, achieved kill percentages higher than $99 \%$, followed by $2 \%$ CHX, with percentages above $96 \%$ (no significant statistical differences). The lowest kill percentage $(85.18 \%)$, in this case proving significantly different from the other groups, was obtained with $0.2 \%$ CLX.

\section{Discussion}

Current management of deep carious lesions involves minimally invasive techniques where only a partial caries removal is performed [3]. These techniques show success in clinical studies and microbiological reports examining bacterial presence after such procedures have demonstrated that the number of microorganisms is reduced after incomplete carious dentin removal and tooth sealing [5-9]. However, the persistence of viable bacteria in dentin after these techniques has raised doubts regarding the long-term effectiveness of treatment [31]. Streptococcus mutans are cariogenic bacteria that may be found on sealed carious dentin [2,6-9]. Using AP-PCR fingerprinting analysis, it has been reported that removing partially carious 

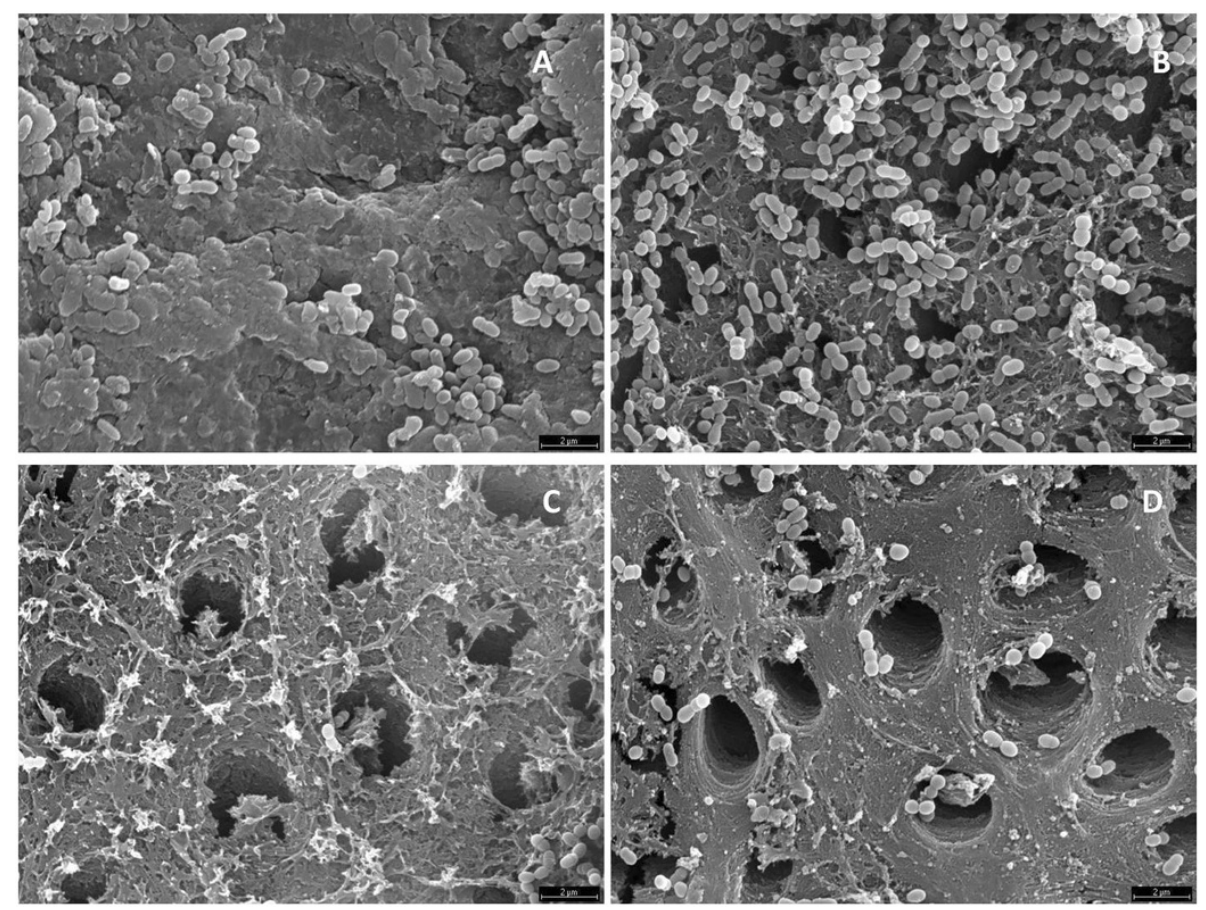

Figure 1 Scanning electron microscopy images of Streptococcus mutans biofilm in the control group (A) and treated with $2 \%$ chlorhexidine (B), $2 \%$ Alexidine (C) and $0.2 \%$ cetrimide (D).

dentin reduces the number of genotypes of these bacteria, but not their cariogenic potential [9]. Therefore, treatment of dentin with an antibacterial agent, before sealing, is useful in eliminating the harmful effects of residual bacteria or bacterial microleakage [10]. Accordingly, our objective was to determine the ability of several antimicrobials in controlling SM biofilm formed in dentin.

Dentin represents the primary substratum for bacterial adhesion and biofilm formation [32], and its interaction with antimicrobial solutions has been clearly shown [11]. As the carrier or biological unit of biofilm formations, we chose a previously tested dentin-volumetric test $[16,22,29]$ in which specimens can be easily size standardized, infected, and handled. At least four specimens may be obtained from each molar, which permits their assignment to different groups, reducing the inherent variability of the sample.

To control dentin infection, one desirable property of antimicrobial agents is their effectiveness against cariogenic bacteria growing as biofilm. In the past decade, antimicrobial agents have been incorporated into dental materials to lend them antimicrobial activity $[33,34]$. The incorporation of CHX and/or CTR into glass ionomer cement (GIC) is known to confer it with beneficial antibacterial properties [34]. It was recently shown that the incorporation of CHX, CTR or both into AH Plus, an endodontic cement, improves antibacterial action against E. faecalis [35]. Using an Agar diffusion test, Nikihl et al. found that the addition of $2 \% \mathrm{CHX}$ to Biodentine enhanced its antibacterial activity against SM, S. aureus, E. faecalis and C. albicans [36], whereas Korkmaz et al. showed that incorporating a $5 \%$ CHX-CTR mixture into conventional dental luting cement may provide greater antibacterial protection against SM and Lactobacillus [37].

For this study we selected three antimicrobial agents. CHX was included because it is considered the gold standard, functioning as a potent metalloproteinase inhibitor [38] while capable of reducing bacterial load substantially $[15,16]$; yet it has not proven effective in eradicating biofilm in dentin [15], or in vitro, even at concentrations as high as $4 \%$ during one minute of exposure [28]. Our results confirmed the well known concentration-effectiveness of CLX and the need to use concentrations higher than the usual one (2\%) to disinfect dentin. Moreover, despite the particular sensitivity of SM to CLX [16] in dentin, 0.2\% CLX did not manage to eradicate the biofilm of any specimen, and the percentage of reduction (85\%) was lower than with the other solutions. These results, to be expected, show that this concentration is not adequate for cavity disinfection.

The lowest kill percentages in our study were seen with $\mathrm{CHX}$ and the 2\% CHX solution; but these did not reach statistically significant differences with respect to ALX and CTR. Six specimens showed eradication with $2 \%$ CHX, a value between those achieved with ALX at concentrations that were five $(0.2 \% \mathrm{ALX})$ to ten times lower $(0.5 \% \mathrm{ALX})$, 
indicating the great antimicrobial potential of ALX. We should stress that the form of bacteria in biofilms makes it less sensitive to antimicrobial agents, and that $\mathrm{CHX}$ can bind to proteins of the extracellular matrix of the biofilm, reducing its activity [39]. Moreover, dentin can inactivate or weaken the antimicrobial effect of CHX [32].

To the best of our knowledge, no studies have tested ALX as a cavity disinfectant. Nevertheless, $1 \%$ and $2 \%$ of ALX used for 1 minute provide longer antimicrobial substantivity against E. faecalis in dentin [22]. We found that no concentration could completely eradicate SM in all the specimens, while concentrations of $2 \%$ and $1 \%$ ALX obtained the highest kill reduction percentage (99.99\%) and eradication, respectively, in 10 and 8 of the twelve specimens, giving statistically significant differences from $0.2 \%$ ALX (99.56\%). Intermediate values were obtained with 0.5\% ALX (99.78\%). The good results with ALX in an exposure time of 1 minute might be attributed in part to the speed of its bactericidal action, given the higher affinity of ALX to lipopolysaccharide and lipoteichoic acids [40]. These results show that ALX can be an effective cavity disinfectant, particularly when techniques of partial caries removal are involved.

Cetrimide, with demonstrated effectiveness in eradicating E. faecalis biofilms [16] and residual antimicrobial activity [29], obtained results similar to $1 \%$ and $2 \%$ ALX. In a study using the same methodology but with E. faecalis biofilms, this antimicrobial solution succeeded in eradicating biofilm on all specimens [16]. The reduced effectiveness of CTR on SM could depend on the special characteristics of these bacteria. As a surfactant with antimicrobial properties which can weaken the cohesive forces of the biofilm, CTR disrupts the extracellular polysaccharide matrix [41]. The surfactant and antimicrobial properties make it effective against E. faecalis biofilms. Unlike E. faecalis however, SM can form a large quantity of extracellular polysaccharides [42], which afford this bacteria a certain ecological advantage.

We conclude that $2 \%$ and $1 \%$ ALX, as well as $0.2 \%$ CTR, achieved eradication of SM biofilm in most of the specimens of our study. In a clinical situation these antimicrobial solutions could be proposed as an alternative to $\mathrm{CHX}$, for therapeutic cavity disinfection when applied for one minute. Given the diversity of the microbiota in carious dentin, and in view of the results described here, future studies should aim to evaluate the effect of different antimicrobial combinations for the control of bacteria involved in dentin caries.

\section{Competing interests}

The authors declare no potential conflicts of interest with respect to the authorship and/or publication of this article.

\section{Authors' contribution}

The study was designed by authors PB, MRL and CMFL, and executed by MRL, MTAM. PC and BA participated in the study design and carried out biofilm and hard tissue preparation. The statistical analysis was done by PB and the article was written by MRL and CMFL and PB. This study is part of the doctoral thesis of BA. The acknowledged person has seen the text and given permission to be named. All authors read and approved the final manuscript.

\section{Acknowledgments}

The authors deny any conflicts of interest related to this study. The authors thank Francisca Castillo Pérez for her technical assistance. This study was supported by Research Group CTS-167 of the Junta de Andalucía, Spain.

\section{Author details}

1Department of Paediatric Dentistry, School of Dentistry, University of Granada, Campus de Cartuja, Colegio Máximo s/n, Granada, Spain. ${ }^{2}$ Department of Dental Pathology and Therapeutics, School of Dentistry, University of Granada, Campus de Cartuja, Colegio Máximo s/n, Granada, Spain. ${ }^{3}$ Department of Microbiology, School of Dentistry, University of Granada, Granada, Spain. ${ }^{4}$ University of Granada, Granada, Spain. ${ }^{5}$ Department of Preventive Dentistry, School of Dentistry, University of Granada, Campus de Cartuja, Colegio Máximo s/n, Granada, Spain.

Received: 9 June 2014 Accepted: 3 August 2014

Published: 20 August 2014

\section{References}

1. Aas JA, Griffen AL, Dardis SR, Lee AM, Olsen I, Dewhirst FE, Leys EJ, Paster $\mathrm{BJ}$ : Bacteria of dental caries in primary and permanent teeth in children and young adults. J Clin Microbiol 2008, 46:1407-1417.

2. Ayna B, Celenk S, Atakul F, Sezgin B, Ozekinci T: Evaluation of clinical and microbiological features of deep carious lesions in primary molars. $J$ Dent Child (Chic) 2003, 70:15-18.

3. Ricketts DN, Kidd EA, Innes N, Clarkson J: Complete or ultraconservative removal of decayed tissue in unfilled teeth. Cochrane Database Syst Rev 2006, 19:CD003808.

4. Kidd EAM: How clean must a cavity be before restoration? Caries Res 2004, 38:305-313.

5. Bjørndal $L$, Larsen $T$ : Changes in the cultivable flora in deep carious lesions following a stepwise excavation procedure. Caries Res 2000, 34:502-508.

6. Orhan Al, Oz FT, Ozcelik B, Orhan K: A clinical and microbiological comparative study of deep carious lesion treatment in deciduous and young permanent molars. Clin Oral Invest 2008, 12:69-78.

7. Lula EC, Monteiro-Neto V, Alves CM, Ribeiro CC: Microbiological analysis after complete or partial removal of carious dentin in primary teeth: a randomized clinical trial. Caries Res 2009, 43:354-358.

8. Duque C, Negrini Tde C, Sacono NT, Spolidorio DM, de Souza Costa CA, Hebling J: Clinical and microbiological performance of resin-modified glass-ionomer liners after incomplete dentine caries removal. Clin Oral Invest 2009, 13:465-471.

9. Damé-Teixeira N, Arthur RA, Parolo CC, Maltz M: Genotypic Diversity and Virulence Traits of Streptococcus mutans Isolated from Carious Dentin after Partial Caries Removal and Sealing. ScientificWorldJournal 2014, 21:165201. doi:10.1155/2014/165201. eCollection 2014.

10. Ersin NK, Uzel A, Aykut A, Candan U: Inhibition of cultivable bacteria by chlorhexidine treatment of dentin lesions treated with the ART technique. Caries Res 2006, 40:172-177.

11. Carrilho MR, Carvalho RM, Sousa EN, Nicolau J, Breschi L, Mazzoni A, Tjäderhane L, Tay FR, Agee K, Pashley DH: Substantivity of chlorhexidine to human dentin. Dent Mater 2010, 26:779-785.

12. Rosenberg L, Atar M, Daronch M, Honig A, Chey M, Funny MD, Cruz L: Prospective study of indirect pulp treatment in primary molars using resin-modified glass ionomer and $2 \%$ chlorhexidine gluconate:a 12 month follow-up. Pediatr Dent 2013, 35:13-17.

13. Järvinen $H$, Pienihäkkinen $K$, Huovinen $P$, Tenovuo J: Susceptibility of Streptococcus mutans and Streptococcus sobrinus to antimicrobial agents after short-term oral chlorhexidine treatments. Eur J Oral Sci 1995, 103:32-35.

14. Mohammadi Z, Abbott PV: The properties and applications of chlorhexidine in endodontics. Int Endod J 2009, 42:288-302. 
15. Borges FC, de Melo MS, Lima JM, Zanin IJ, Rodrigues LA: Antimicrobial effect of chlorhexidine digluconate in dentin: in vitro and in situ study. J Conserv Dent 2012, 15:22-26.

16. Baca P, Junco P, Arias-Moliz MT, González-Rodríguez MP, Ferrer-Luque CM: Residual and antimicrobial activity of final irrigation protocols on Enterococcus faecalis biofilm in dentin. J Endod 2011, 37:363-366.

17. McDonnell G, Russell AD: Antiseptics and disinfectants: activity, action, and resistance. Clin Microbiol Rev 1999, 12:147-179.

18. Roberts WR, Addy M: Comparison of the bisbiguanide antiseptics alexidine and chlorhexidine: I. Effect on plaque accumulation and salivary bacteria. J Clin Periodontol 1981, 8:213-219.

19. Yanai R, Ueda K, Nishida T, Toyohara M, Mori O: Effects of tonicity-adjusting and surfactant agents on the antimicrobial activity of alexidine. Eye Contact Lens 2011, 37:57-60.

20. Kim HS, Woo Chang S, Baek SH, Han SH, Lee Y, Zhu Q, Kum KY: Antimicrobial effect of alexidine and chlorhexidine against Enterococcus faecalis infection. Int J Oral Sci 2013, 5:26-31.

21. Silveira LF, Baca P, Arias-Moliz MT, Rodríguez-Archilla A, Ferrer-Luque CM: Antimicrobial activity of alexidine alone and associated with $\mathrm{N}$ acetylcysteine against Enterococcus faecalis biofilm. Int J Oral Sci 2013, 5:146-149.

22. Barrios R, Ferrer-Luque CM, Arias-Moliz MT, Ruiz-Linares M, Bravo M, Baca P. Antimicrobial substantivity of alexidine and chlorhexidine in dentin. J Endod 2013, 39:1413-1415.

23. Alizadeh $\mathrm{H}$, Neelam S, Cavanagh HD: Amoebicidal activities of alexidine against 3 pathogenic strains of acanthamoeba. Eye Contact Lens 2009, $35: 1-5$.

24. Vieira DB, Carmona-Ribeiro AM: Cationic lipids and surfactants as antifungal agents: mode of action. J Antimicrob Chemother 2006, 58:760-767.

25. Cloete TE, Jacob L, Brozel VS: The chemical control of biofouling in industrial water systems. Biodegradation 1998, 9:23-37.

26. Giardino L, Ambu E, Becce C, Rimondini L, Morra M: Surface tension comparison of four common root canal irrigants and two new irrigants containing antibiotic. J Endod 2006, 32:1091-1093.

27. Onçağ $\mathrm{O}$, Hoşgör M, Hilmioğlu S, Zekioğlu O, Eronat C, Burhanoğlu D: Comparison of antibacterial and toxic effects of various root canal irrigants. Int Endod J 2003, 36:423-432.

28. Arias-Moliz MT, Ferrer-Luque CM, González-Rodríguez MP, Valderrama MJ, Baca P: Eradication of Enterococcus faecalis biofilms by cetrimide and chlorhexidine. J Endod 2010, 36:87-90.

29. Baca P, Junco P, Arias-Moliz MT, Castillo F, Rodríguez-Archilla A, FerrerLuque CM: Antimicrobial substantivity over time of chlorhexidine and cetrimide. J Endod 2012, 38:927-930.

30. Botelho MG: The antimicrobial activity of a dentin conditioner combined with antibacterial agents. Oper Dent 2005, 30:75-82.

31. Weerheijm KL, Kreulen CM, de Soet JJ, Groen HJ, van Amerongen WE: Bacterial counts in carious dentine under restorations: 2-year in vivo effects. Caries Res 1999, 33:130-134.

32. Haapasalo M, Qian W, Portenier I, Waltimo T: Effects of dentin on the antimicrobial properties of endodontic medicaments. J Endod 2007, 33:917-925.

33. Imazato S: Antibacterial properties of resin composites and dentin bonding systems. Dent Mater 2003, 19:449-457.

34. Tüzüner T, Kuşgöz A, Er K, Taşdemir T, Buruk K, Kemer B: Antibacterial activity and physical properties of conventional glass-ionomer cements containing chlorhexidine diacetate/cetrimide mixtures. J Esthet Restor Dent 2011, 23:46-55

35. Bailón-Sánchez ME, Baca P, Ruiz-Linares M, Ferrer-Luque CM: Antibacterial and anti-biofilm activity of $\mathrm{AH}$ Plus with chlorhexidine and cetrimide. J Endod 2014, 40:977-981.

36. Nikhil V, Madan M, Agarwal C, Suri N: Effect of addition of $2 \%$ chlorhexidine or $10 \%$ doxycycline on antimicrobial activity of biodentine. J Conserv Dent 2014, 17:271-275.

37. Korkmaz FM, Tüzüner T, Baygin O, Buruk CK, Durkan R, Bagis B: Antibacterial activity, surface roughness, flexural strength, and solubility of conventional luting cements containing chlorhexidine diacetate/ cetrimide mixtures. J Prosthet Dent 2013, 110:107-115.

38. Gendron R, Grenier D, Sorsa T, Mayrand D: Inhibition of theactivities of matrix metalloproteinases 2, 8 and 9 by chlorhexidine. Clin Diagn Lab Immunol 1999, 6:437-439.
39. Kara D, Luppens SB, van Marle J, Ozok R, ten Cate JM: Microestructural differences between single-species and dual-species biofilm of Streptococcus mutans and Veionella parvula, before and after exposure to chlorhexidine. FEMS Microbiology Lett 2007, 271:90-97.

40. Zorko M, Jerala R: Alexidine and Chlorhexidine bind to lipopolysaccharide and lipoteichoic acid and prevent cell activation by antibiotics. J Antimicrob Chemother 2008, 62:730-737.

41. Simoes M, Pereira MO, Vieira MJ: Effects of mechanical stress on biofilms challenged by different chemical. Water Res 2005, 39:5142-5152.

42. Bowen $\mathrm{WH}, \mathrm{KoO} \mathrm{H}$ : Biology of Streptococcus mutans-derived glucosyltransferases: role in extracellular matrix formation of cariogenic biofilms. Caries Res 2011, 45:69-86.

\section{doi:10.1186/s12941-014-0041-5}

Cite this article as: Ruiz-Linares et al: Antimicrobial activity of alexidine, chlorhexidine and cetrimide against Streptococcus mutans biofilm. Annals of Clinical Microbiology and Antimicrobials 2014 13:41.

\section{Submit your next manuscript to BioMed Central and take full advantage of:}

- Convenient online submission

- Thorough peer review

- No space constraints or color figure charges

- Immediate publication on acceptance

- Inclusion in PubMed, CAS, Scopus and Google Scholar

- Research which is freely available for redistribution 